\title{
GMR
}

\section{miR-129b suppresses cell proliferation in the human lung cancer cell lines A549 and H1299}

\author{
L. Zheng, Y.X. Qi, S. Liu, M.L. Shi and W.P. Yang \\ Department of Respiratory Medicine, People's Hospital of Laiwu City, \\ Laiwu, Shandong Province, China \\ Corresponding author: L. Zheng \\ E-mail: drliang201500@sina.com
}

Genet. Mol. Res. 15 (4): gmr15048367

Received December 29, 2015

Accepted September 5, 2016

Published October 17, 2016

DOI http://dx.doi.org/10.4238/gmr15048367

Copyright (C) 2016 The Authors. This is an open-access article distributed under the terms of the Creative Commons Attribution ShareAlike (CC BY-SA) 4.0 License.

\begin{abstract}
Lung cancer is one of the most prevalent malignant tumors, and is one of the primary causes of cancer-associated deaths. In 2002, an estimated 1.18 million lung cancer-associated deaths were recorded, accounting for $18 \%$ of cancer-related deaths and $2 \%$ of total mortality. Despite the great progress that has been made in lung cancer therapies, the mechanisms underlying lung cancer formation and development remain largely unknown. Meanwhile, the microRNA miR-129 has been shown to be involved in the formation of many types of cancer. Therefore, this study aims to investigate whether miR129b could suppress proliferation of lung cancer cell lines. NSCLC tissue samples were collected from the Department of Respiratory Medicine between April 2013 and December 2015. Ten normal health individuals were recruited as controls. Lung cancer cell lines A549 and H1299 were used to examine the suppressive effects of miR129b. Quantitative real-time PCR was used to detect miR129b expression. The MTT assay was used to analyze cell proliferation. Results indicated that miR$129 \mathrm{~b}$ is down-regulated in lung cancer cell lines and NSCLC tissues.
\end{abstract}


Furthermore, overexpression of miR-129b inhibited proliferation of lung cancer cells. In conclusion, miR-129b suppresses lung cancer cell proliferation, and can be a potential therapeutic target for treatment of lung cancers.

Key words: Non-small cell lung carcinoma; miR-129b; Lung cancer; Cancer cell proliferation

\section{INTRODUCTION}

Cancer is among one of the deadliest diseases in the world with poor prognosis. Lung cancer is one of the most common causes of cancer-related death in humans, and non-small cell lung cancer (NSCLC) represents nearly $80 \%$ of all cases (Spira and Ettinger, 2004; Siegel et al., 2013). In 2002, an estimated 1.18 million lung cancer deaths were recorded, accounting for $18 \%$ of cancer deaths and $2 \%$ of total mortality. Surgical resection is the primary treatment for NSCLC patients. However, most patients are only diagnosed at advanced or metastatic stages where surgical resection is no longer an option; regular cytotoxic chemotherapy is the best treatment for these patients, even though prognosis is rather poor (Zhang et al., 2012; Poghosyan et al., 2013). Scientists have been trying to uncover the molecular mechanisms underlying lung cancer formation, and a number of oncogene and tumor suppressor genes have been suggested to participate in this process. These studies provide insights into lung cancer tumorigenesis and promote the development of novel therapeutic strategies. Although tremendous efforts have been made in this field, the mechanisms underlying lung cancer formation are yet to be uncovered.

MicroRNAs (miRNAs) are a group of evolutionarily conserved small non-coding RNAs. miRNAs target 3'-untranslated regions of messenger RNAs (mRNAs) to posttranscriptionally regulate the expression of target genes by inhibiting translation and promoting mRNA cleavage. miRNAs have been shown to participate in a variety of biological processes, including growth, differentiation, apoptosis, and formation of malignancies, all of which are essential biological processes in cancer progression and metastasis (Garzon et al., 2009; Krol et al., 2010; Almeida et al., 2011; Munker and Calin, 2011; Zhang et al., 2016). Aberrant miRNA expression has been shown to be involved in carcinogenesis (Di Leva and Croce, 2010; Hu et al., 2010; Zhou et al., 2016). As increasing number of studies show that miRNAs may serve as diagnostic biomarkers and therapeutic targets for cancers, it is recognized that miRNAs may play essential roles in the formation, progression, and metastasis of cancers.

miR-129 has been shown to be involved in the formation of many types of cancer. For instance, it was found to be down-regulated in undifferentiated gastric cancer (Katada et al., 2009), and was also reported to be down-regulated in other forms of cancer, including colorectal cancer (Tsai et al., 2011; Karaayvaz et al., 2013), gastric cancer (Liu et al., 2012), and liver cancer (Bandres et al., 2009; Tsai et al., 2011; Liu et al., 2012; Karaayvaz et al., 2013). miR-129 down-regulation is tightly associated with disease stages and progression, and its down-regulation is attributed to hypermethylation of its promoter (Yu et al., 2013). Similar down-regulation in miR-129 was also observed in hepatocellular carcinoma (Lu et al., 2013; Chen, et al., 2013). These results suggest that miR-129 plays a crucial role in tumorigenesis.

In this study, we demonstrated that miR-129b inhibitslung cancer cell growth, and is down-regulated in lung cancers, suggesting that it may be an important tumor suppressor.

Genetics and Molecular Research 15 (4): gmr15048367 


\section{MATERIAL AND METHODS}

\section{Patients and ethics statement}

NSCLC tissue samples (from 11 patients) were collected from the Department of Respiratory Medicine, People's Hospital of Laiwu City between April 2013 and December 2015. Eight male patients and three female patients were included in the study. Ten healthy individuals were recruited as controls. Clinical and pathological classification/stage was determined according to criteria set by the American Joint Committee on Cancer.

This study was approved by the Ethics Committee of People's Hospital of Laiwu City. Informed consent was obtained from each patient, and the study protocol conformed to ethical guidelines outlined by the Declaration of Helsinki of 1975.

\section{Inclusion and exclusion criteria}

Inclusion criteria were as follows: i) all patients must have received standard adjuvant therapy after surgery, including chemotherapy and radiotherapy; ii) complete tumor resection was described in the surgical record, with an expected DFS of $>3$ months; iii) diagnoses of NSCLC were confirmed by post-operative pathologic results; iv) all patients must have accepted periodic review following therapy, and have been followed-up for no less than 2 years; v) pathological specimens preserved in paraffin were available.

Exclusion criteria were as follows: i) any delay in adjuvant therapy; ii) any dysfunction of the heart, liver, kidney, or lung after the surgery; iii) degradation of RNA in any pathological specimens, and iv) patient death from treatment-related complications.

\section{Cell lines}

Lung cancer cell lines A549 and H1299 were purchased from the American Type Culture Collection (ATCC). The normal human bronchial epithelial cell line HBE was also purchased from ATCC. All cell lines were cultured in Dulbecco's Modified Eagle Medium (Gibco) supplemented with $10 \%$ fetal bovine serum (FBS) in a $37^{\circ} \mathrm{C}$ incubator with $95 \% \mathrm{O}_{2}$ and $5 \% \mathrm{CO}_{2}$.

\section{Quantitative real-time PCR}

RNA samples were extracted from cells using TRIZOL reagent following manufacturer instructions (Invitrogen, USA). RNA samples were reverse-transcribed to cDNA using the SuperScript III kit (Invitrogen). Expression levels of miR-129b were measured by quantitative real-time polymerase chain reaction (qRT-PCR) with the SYBR Green PCR Master Mix kit (Applied Biosystems, USA).

The primers used were follows: miR129-b forward primer: 5'-GAGTTGGGGGATCGC GGAC-3', reverse primer: 5'-ATATACCGACTTCTTCGATTCGCCG-3'; GAPDH forward primer: 5'-ACCACAGTCCATGCCATCACA-3'; reverse primer: 5'-TCCACCACCCTGTTG CTGTA-3'. Primers were synthesized by Sangon Inc. Co. (Shanghai, China). The PCR cycling parameters were as follows: $94^{\circ} \mathrm{C}$ for $30 \mathrm{~s}$, annealing at $60^{\circ} \mathrm{C}$ for $30 \mathrm{~s}$, and extension at $72^{\circ} \mathrm{C}$ for $60 \mathrm{~s}$, for a total of 40 cycles. RT-PCR was performed using the LightCycler 480 system (Roche Applied Science, Penzberg, Germany).

Genetics and Molecular Research 15 (4): gmr15048367 
Glyceraldehyde 3-phosphate dehydrogenase (GAPDH) was used as the internal control gene in this study. Expression levels of miR-129b in lung cell lines were normalized to that in HBE. PCR products were run on $1.5 \%$ agarose gels; images were digitally captured with a CCD camera and analyzed with the NIH Imager beta version 2.0 software.

\section{Lentiviral vector production and transfection}

The oligonucleotides of miR-129b mimics and its nonspecific control were purchased from RiboBio (RiboBio, St. Louis, MO, USA). To generate lentiviral vectors, miR-129b mimics (miR-129b-tranfected A549 or H1299 group) (equal to the primer sequence of RTPCR for miR129) and non-specific oligonucleotides (NC-transfected A549 or H1299 group) were cloned into pCDHCMV-MCS-EF1-coGFP constructs (System Biosciences) via insertion into the BamHI and EcoRI restriction sites. The lentiviral vectors were co-transfected into HEK293 cells with pPACK, the packaging plasmid. Viral particles of miR-129b mimics and nonspecific miRNA were titred prior to being transfected into A549 and H1299 cells. Lipofectamine 2000 was used for transfection following manufacturer instructions (Invitrogen). Primers of miR-129b mimics were designed according to unrelated gene fragments, and were as follows: forwards primer: 5'-GGTGGATTCAGAACGTTCACTGE-3', reverse primer: 5'-TCATCACTTGGTGACTAGCAAC-3'.

\section{MTT assay}

A549 and H1299 cells were seeded on 96-well plates for $24 \mathrm{~h}$ at $37^{\circ} \mathrm{C}$, and were incubated with lentiviruses for six days. The culture medium was then replaced by $100 \mu \mathrm{L}$ DMEM $+10 \%$ FBS. MTT solution $(20 \mu \mathrm{L})$ was added, and cells were incubated for $2 \mathrm{~h}$ following manufacturer's instructions (Sigma-Aldrich, USA). The total number of viable cells was determined by absorbance at $490 \mathrm{~nm}$.

\section{Statistical analysis}

All experiments were performed in triplicates. Data are reported as means \pm SD. Statistical differences were analyzed using the Student t-test. P value $<0.05$ was considered to be statistically significant.

\section{RESULTS}

\section{miR-129b is down-regulated in lung cancer cell lines and NSCLC tissues}

miR-129 was found to be down-regulated in many types of human cancer, and this phenomenon is closely associated with disease progression. Here we examined the expression of miR-129b in the lung cell lines A549 and H1299 via qRT-PCR. The expression levels of miR-129b in normal human bronchial epithelial cell line HBE were used as controls. Results showed that miR-129b expression was markedly reduced in lung cancer cell lines as compared with that in the control cell line (Figure 1). Consistent with this result, we also observed lower expression of miR-129b in NSCLC tissues as compared with non-tumorigenic controls (Figure 1). These results indicated a potential regulatory role of miR-129b in lung cancer.

Genetics and Molecular Research 15 (4): gmr15048367 


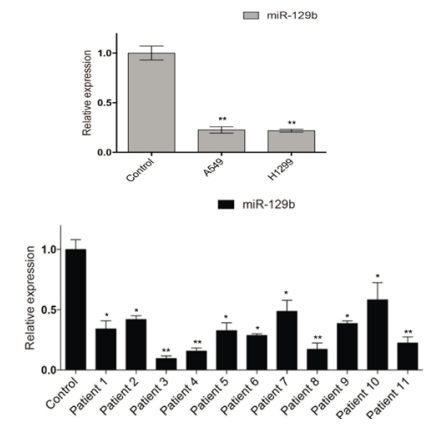

Figure 1. miR-129b is down-regulated in human lung cancer cell lines and NSCLC tissues. Total RNA samples were isolated from human lung cancer cell lines, A549 and H1299, as well as NSCLC tissues. RNA samples extracted from the normal human bronchial epithelial cell line HBE and non-tumorigenic tissues served as controls. All the samples were measured by quantitative real-time PCR. $* \mathrm{P}<0.05$ and $* * \mathrm{P}<0.01$ represent the relative expression of miR129b in lung cancer lines or patients as compared to that in respective controls.

\section{Overexpression of miR-129b inhibits the proliferation of lung cancer cells}

We next set to examine the role of miR-129b in lung cancer cells. We transfected A549 and H1299 cells with lentivirus containing miR-129b. Nonspecific miRNAs were also transfected into A549 cells and H1299 cells as controls. Total RNA in transfected cells was extracted, and qRT-PCR was performed to determine miR-129b expression. The data showed that expression of miR-129b was significantly increased in miR-129b-transfected cells as compared with those transfected with non-specific miRNA (Figure 2A).

We next performed MTT assay to examine proliferation of A549 and H1299 cells with elevated expression of miR-129b. Results showed that proliferation rate was greatly reduced in A549 cells and H1299 cells transfected with miR-129b as compared with cells transfected with nonspecific miRNA (Figure 2B and C). These results demonstrated that miR-129b plays an inhibitory role in the regulation of lung cancer cell proliferation.

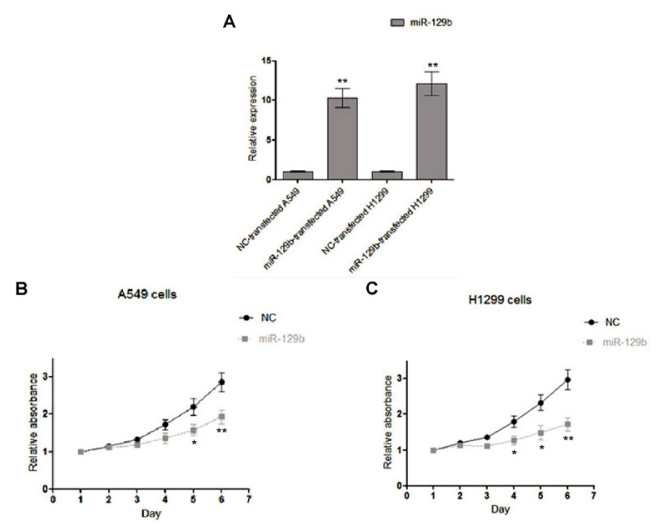

Figure 2. Overexpression of miR-129b suppresses human lung cancer cell proliferation. A. qRT-PCR results showing that overexpression of miR-129b in A549 and H1299 transfected with miR-129b lentivirus as compared with that of controls. B. MTT assay showing that overexpression of miR-129b suppressed A549 cell proliferation. C. MTT assay showing that overexpression of miR-129b suppressed $\mathrm{H} 1299$ cell proliferation. $* \mathrm{P}<0.05$ and $* * \mathrm{P}<0.01$ represent relative expression of miR129b in miR129b-transfected group as compared with NC group. NC: non-specific oligonucleotides.

Genetics and Molecular Research 15 (4): gmr15048367 


\section{DISCUSSION}

Lung cancer is a major cause of cancer related mortality worldwide. There were approximately 270,000 patients who died from lung cancer in the European Union in 2013 (Malvezzi et al., 2013). A majority of lung cancer patients are diagnosed at advanced stages of disease, and thus can only be treated with palliative chemotherapy. The survival rate is very low. NSCLC is a major type of human lung cancer.

The role of miRNAs in lung carcinogenesis was first established in 2004. Calin et al. (2004) demonstrated that many miRNA genes are located in cancer-associated genomic regions or in fragile sites. Takamizawa et al. (2004) also observed that let-7 microRNA is down-regulatedin human NSCLC. This result was also consistent with the other studies (Johnson et al., 2005; Yanaihara et al., 2006; Inamura et al., 2007). Down-regulation of let-7a in lung cancer is closely associated with up-regulation of the RAS protein. Aside from let-7, other miRNAs may also interact with RAS. For instance, miR-451 was shown to be downregulated in NSCLC, which correlated with low survival (Wang et al., 2011). In another study, miR-17-92 cluster was reported to be dramatically overexpressed in lung cancers, which promoted cell proliferation (Hayashita et al., 2005). In summary, an increasing number of studies have shown that miRNAs may play essential roles in cancer biology.

Although we have obtained some interesting results in this study, there are also a few limitations. First, the study focused on only two lung cancer cell lines; additional cell lines must be studied for sufficient conclusion. Second, this study only examined the function of miR-129b in inhibiting proliferation of NSCLC cells. However, the specific mechanism of miR-129b role in NSCLC pathology has yet to be investigated. In the following study, we would like to determine the mechanism of miR-129b in NSCLC pathology using other cell lines and large patient samples. Third, the role of miR129 was not fully clarified. Given the abundance of data indicating the importance of miR129, it would be interesting to examine it under in vivo settings, and determine miR129 affects expression levels of relevant genes at mRNA and protein levels.

In this study, we showed that miR-129b was significantly down-regulated in lung cancers, and that overexpression of miR-129b suppressed lung cancer cell proliferation. Based on our findings, we speculate that miR129 therapy may be used as a treatment or diagnostic marker to improve early detection of lung cancer. However, clinical application of miR129 need to be further investigated in future studies. Our study provides a new biomarker and potential therapeutic target for lung cancer treatment. However, the mechanism by which miR-129b regulates lung cancer cell proliferation is still unknown, and further investigation is needed.

\section{Conflicts of interest}

The authors declare no conflict of interest.

\section{ACKNOWLEDGMENTS}

We thank all of our lab members for helpful discussions and critical comments on this study. Research supported by the People's Hospital of Laiwu City, and was approved by the Medical Scientific Research Foundation of Guangdong Province (Grant \#B2014360) as well as the Scientific Research Project of Shenzhen Health Bureau (Grant \#201402043)

Genetics and Molecular Research 15 (4): gmr15048367 


\section{REFERENCES}

Almeida MI, Reis RM and Calin GA (2011). MicroRNA history: discovery, recent applications, and next frontiers. Mutat. Res. 717: 1-8. http://dx.doi.org/10.1016/j.mrfmmm.2011.03.009

Bandres E, Agirre X, Bitarte N, Ramirez N, et al. (2009). Epigenetic regulation of microRNA expression in colorectal cancer. Int. J. Cancer 125: 2737-2743. http://dx.doi.org/10.1002/ijc.24638

Calin GA, Sevignani C, Dumitru CD, Hyslop T, et al. (2004). Human microRNA genes are frequently located at fragile sites and genomic regions involved in cancers. Proc. Natl. Acad. Sci. USA 101: 2999-3004.http://dx.doi.org/10.1073/ pnas. 0307323101

Chen X, Zhang L, Zhang T, Hao M, et al. (2013). Methylation-mediated repression of microRNA 129-2 enhances oncogenic SOX4 expression in HCC. Liver Int. 33: 476-486. http://dx.doi.org/10.1111/liv.12097

Di Leva G and Croce CM (2010). Roles of small RNAs in tumor formation. Trends Mol. Med. 16: 257-267.http://dx.doi. org/10.1016/j.molmed.2010.04.001

Garzon R, Calin GA and Croce CM (2009). MicroRNAs in Cancer. Annu. Rev. Med. 60: 167-179. http://dx.doi.org/10.1146/ annurev.med.59.053006.104707

Hayashita Y, Osada H, Tatematsu Y, Yamada H, et al. (2005). A polycistronic microRNA cluster, miR-17-92, is overexpressed in human lung cancers and enhances cell proliferation. Cancer Res. 65: 9628-9632. http://dx.doi. org/10.1158/0008-5472.CAN-05-2352

Hu Z, Chen X, Zhao Y, Tian T, et al. (2010). Serum microRNA signatures identified in a genome-wide serum microRNA expression profiling predict survival of non-small-cell lung cancer. J. Clin. Oncol. 28: 1721-1726. http://dx.doi. org/10.1200/JCO.2009.24.9342

Inamura K, Togashi Y, Nomura K, Ninomiya $\mathrm{H}$, et al. (2007). let-7 microRNA expression is reduced in bronchioloalveolar carcinoma, a non-invasive carcinoma, and is not correlated with prognosis. Lung Cancer 58: 392-396. http://dx.doi. org/10.1016/j.lungcan.2007.07.013

Johnson SM, Grosshans H, Shingara J, Byrom M, et al. (2005). RAS is regulated by the let-7 microRNA family. Cell 120: 635-647.http://dx.doi.org/10.1016/j.cell.2005.01.014

Karaayvaz M, Zhai H and Ju J (2013). miR-129 promotes apoptosis and enhances chemosensitivity to 5-fluorouracil in colorectal cancer. Cell Death Dis. 4: e659. http://dx.doi.org/10.1038/cddis.2013.193

Katada T, Ishiguro H, Kuwabara Y, Kimura M, et al. (2009). microRNA expression profile in undifferentiated gastric cancer. Int. J. Oncol. 34: 537-542.

Krol J, Loedige I and Filipowicz W (2010). The widespread regulation of microRNA biogenesis, function and decay. Nat. Rev. Genet. 11: 597-610.

Liu Y, Hei Y, Shu Q, Dong J, et al. (2012). VCP/p97, down-regulated by microRNA-129-5p, could regulate the progression of hepatocellular carcinoma. PLoS One 7: e35800. http://dx.doi.org/10.1371/journal.pone.0035800

Lu CY, Lin KY, Tien MT, Wu CT, et al. (2013). Frequent DNA methylation of MiR-129-2 and its potential clinical implication in hepatocellular carcinoma. Genes Chromosomes Cancer 52: 636-643.

Malvezzi M, Bertuccio P, Levi F, La Vecchia C, et al. (2013). European cancer mortality predictions for the year 2013. Ann. Oncol. 24: 792-800.http://dx.doi.org/10.1093/annonc/mdt010

Munker R and Calin GA (2011). MicroRNA profiling in cancer. Clin. Sci. 121: 141-158. http://dx.doi.org/10.1042/ CS20110005

Poghosyan H, Sheldon LK, Leveille SG and Cooley ME (2013). Health-related quality of life after surgical treatment in patients with non-small cell lung cancer: a systematic review. Lung Cancer 81: 11-26. http://dx.doi.org/10.1016/j. lungcan.2013.03.013

Siegel R, Naishadham D and Jemal A (2013). Cancer statistics, 2013. CA Cancer J. Clin. 63: 11-30. http://dx.doi. org $10.3322 /$ caac. 21166

Spira A and Ettinger DS (2004). Multidisciplinary management of lung cancer. N. Engl. J. Med. 350: 379-392. http:// dx.doi.org/10.1056/NEJMra035536

Takamizawa J, Konishi H, Yanagisawa K, Tomida S, et al. (2004). Reduced expression of the let-7 microRNAs in human lung cancers in association with shortened postoperative survival. Cancer Res. 64: 3753-3756. http://dx.doi. org/10.1158/0008-5472.CAN-04-0637

Tsai KW, Wu CW, Hu LY, Li SC, et al. (2011). Epigenetic regulation of miR-34b and miR-129 expression in gastric cancer. Int. J. Cancer 129: 2600-2610. http://dx.doi.org/10.1002/ijc.25919

Wang R, Wang ZX, Yang JS, Pan X, et al. (2011). MicroRNA-451 functions as a tumor suppressor in human non-small cell lung cancer by targeting ras-related protein 14 (RAB14). Oncogene 30: 2644-2658. http://dx.doi.org/10.1038/ onc. 2010.642

Genetics and Molecular Research 15 (4): gmr15048367 
Yanaihara N, Caplen N, Bowman E, Seike M, et al. (2006). Unique microRNA molecular profiles in lung cancer diagnosis and prognosis. Cancer Cell 9: 189-198. http://dx.doi.org/10.1016/j.ccr.2006.01.025

Yu X, Song H, Xia T, Han S, et al. (2013). Growth inhibitory effects of three miR-129 family members on gastric cancer. Gene 532: 87-93. http://dx.doi.org/10.1016/j.gene.2013.09.048

Zhang HC, Song YF, Ye J, Lai GX, et al. (2016). MicroRNA-154 functions as a tumor suppressor and directly targets HMGA2 in human non-small cell lung cancer. Genet. Mol. Res. 15: gmr.15028173.

Zhang J, Xue ZQ, Chu XY, Wang YX, et al. (2012). Surgical treatment and prognosis of octogenarians with non-small cell lung cancer. Asian Pac. J. Trop. Med. 5: 465-468. http://dx.doi.org/10.1016/S1995-7645(12)60079-0

Zhou X, Zhang L, Zheng B, Yan Y, et al. (2016). MicroRNA-761 is upregulated in hepatocellular carcinoma and regulates tumorigenesis by targeting mitofusin-2. Cancer Sci. 107: 424-432.

Genetics and Molecular Research 15 (4): gmr15048367 